Euskal ikerketen aldizkaria | Revue d'études basques |

Revista de estudios vascos | Basque studies review

$11 \mid 2006$

Numéro XI

\title{
Txillardegi : Leturia-ren 50. urtemuga (1957 - 2007)
}

\section{Gorka Aulestia}

\section{OpenEdition}

\section{Journals}

Édition électronique

URL : http://journals.openedition.org/lapurdum/212

DOI : 10.4000/lapurdum. 212

ISSN : 1965-0655

Éditeur

IKER

Édition imprimée

Date de publication : 1 novembre 2006

Pagination : 41-47

ISBN : 978-2-86781-474-7

ISSN : $1273-3830$

\section{Référence électronique}

Gorka Aulestia, «Txillardegi : Leturia-ren 50. urtemuga (1957 - 2007)», Lapurdum [Linean], 11 | 2006

Sarean emana---an 01 avril 2008, kontsultatu 23 avril 2019. URL : http://journals.openedition.org/ lapurdum/212 ; DOI : 10.4000/lapurdum.212 


\title{
Txillardegi: Leturia-ren 50. urtemuga (1957-2007)
}

\author{
Gorka AULESTIA \\ EHU
}

Inoiz ez da erraza izaten idazle polifazetiko baten ibilbideari hurbiletik jarraitzea, zeren orain darabilgun kasuan argitaratu baititu hogeita hamar liburu baino gehiago (politika, soziolinguistika eta literatura gaiei buruzkoak) eta ehundaka entsaio eta artikulu, gehienak euskal aldizkari eta egunkarietan, batez ere Egan, Branka, Zeruko Argia, Enbata, Jakin, Egin eta Euskaldunon Egunkaria-n. Jarraipen hau are zailago gertatzen zaigu idazlea zenbait izengoitiz baliatu delako (batzuetan klandestinitatearen garaian bere nortasuna ezkutatzeko): "Txillardegi", "Larresoro", "Igara", "Harribizketa", "Usako", "Goihenetxe", "Ehialarre" eta "Txubillo". Literatura arloan genero guztiak jorratu ditu poesia eta antzerkia izan ezik. Hizkuntzalaritza arloan lexiko, morfologia, fonetika eta prosodiaz egin dituen lanak nabarmentzen dira. Beste alde batetik, soziolinguistikari buruzko Bat aldizkariaren zuzendari dugu eta baditu 63 zenbaki aterata. Politika arloan Ekin eta ETA talde independentisten sortzailekidea izan zen. 2000. urteko udan unibertsitatetik erretiratu izanak aukera ona ematen digu euskaldunberri honen lan handiaren balantzea egiteko batik bat gure azken helburua kontuan hartuz: bere obraren alderdi literarioa.

Bere bizitzari buruzko oharrik aipagarrienak honako hauek izan litezke: XX. mendeko bigarren zatian nahitaezko erreferentzia dugu politika, hizkuntzalaritza eta literatura eremuetan; euskal abertzalea eta independista; irakaslea eta idazle konprometitua; euskaltzale porrokatua; euskal nobela modernoaren aitzindaria; karreraz industria ingeniaria baina bokazioz eta lanbidez hizkuntzalaria; uste sendoak izan dituen intelektuala; hizkuntza gutxituen eta Estaturik gabeko nazioen defendatzaile sutsua; idazle argi eta sakona. Bere ezaugarri pertsonalen artean hurrengook aipa ditzakegu: nortasun handiko gizona; gai erlijiosoaz kezkatuta dagoen agnostikoa; tematia baina okerrak aitortzen dakiena; bere baieztapenetan zehatza; borroka dialektiko eta ideologikoan gogorra, baina harreman pertsonaletan otzana; izpiritu libre eta intsumisoduna, aldi berean nolabaiteko anarkismo ñabardura duena; naturazale eta bakardadezalea; sentiberatasun fineko pianojolea; eta, azkenik, bere aberria, Euskal Herria, eta bere hizkuntza, euskara, biziki maite dituena. 
Bere baieztapenetako batzuek goiko lerroetan adierazitakoa berresten dute. Erlijio sinesmenari dagokionez, agnostikoa dela agertzen du: "Ni neu agnostikoa naiz". . Bere ideologia politikoaz baieztatzen du: "Nik hautua egin nuen: euskaldun eta abertzalea izatea... Baina nik hautua egin nuen gaztetan herri zafratu eta iraindu honen alde"2. Ideia filosofikoei buruz, bere burua existentzialistatzat jotzen du: "Ni existentzialista abertzalea naiz: eta intelektual konprometitua, engagé frantsesez"3. Literaturaren balorazioaz eta bere zeregin literarioaz honela mintzatu da: "Nik uste dut literatura beti gauza marginal gisa hartu dudala neure egitekoen artean"4. Euskal Herria eraikitzeko euskarak duen garrantziaz, zalantzarik gabe aldarrikatzen du :"Euskarak egiten gaitu euskaldun, euskarak egiten du herri Euskal Herria"s.

José Luís Álvarez Enparantza, "Txillardegi", Donostiako Antiguo auzoan 1929ko irailaren 27an jaio zen. Zortzi urte zituela, bere hiriko Marianisten ikastetxean sartu zen. Hor batxillergoa egiteko prestatu zen eta 1946an Valladoliden titulua eskuratu zuen. "Txillardegi" jaiotzaz ez da euskaldun, euskaldunberri baizik. 1948an ezerezetik hasita, zazpi urtez (1948-1955) euskara ikasteari gogor ekin zion. 1949. urtean (20 urte zituela) Bilbora joan zen ingeniaritza industrialeko ikasketak egitera eta han euskal hizkuntza eta literatura alorreko pertsona garrantzitsuak hurbiletik ezagutu zituen, hala nola, R.M. Azkue, F. Krutwig, G. Aresti, X. Gereño eta A. Irigoien. Bere unibertsitate ikasketen kaltetan gabe, eta loari ordu asko kenduta, euskal hizkuntza ikasteari bete-betean eutsi zion: "...gauez ikasten nuen euskara: hamabietatik hirurak arte (sic); eta inolako irakaslerik gabe"6. Gazte donostiar honentzako beste bi gai interesgarriak Euskal Herriaren historia [C. Etxegarai, A. Campión, H. Oloriz, F. Sagarmínaga (1830-1894), J. Iturralde y Suit eta Anacleto Ortueta (1877-1959)] eta existentzialismoa (S. Kierkergaard, K Jaspers, M. Heidegger, J.P. Sartre eta M. de Unamuno). "Unamuno euskal herritarra gorroto banuen ere, Unamuno idazlea benetan miresten bainuen"7.

1952. urtearen bukaera aldean, unibertsitateko beste lagun batzuekin batera, Txillardegik Ekin talde politikoa sortu zuen, geroago ETA (Euskadi ta Askatasuna) bihurtuko zena. 1956an unibertsitateko karrrera amaituta, eta El Ferrolen unibertsitate miliziako aldia alferiz mailaz eginda, L. Michelena irakaslearen gonbiteari esker, Gipuzkoako Diputazioan euskara ikastaroak ematen hasi zen. Bere bizitzan 1957. urtea aipagarria da hiru gertaera garrantzitsu bildu baitziren: Jone Forcada, bere lau seme-alabaren ama izango zena, emaztetzat hartu zuen; Leturiaren egunkari ezkutua nobelaren argitalpena eta irailaren 26ko euskaltzain izendapena, hain justu 28 urte bete baino egun bat lehenago. 1959 eta 1960 urteen artean beste bi gertaera garrantzitsu ditugu: bere bigarren nobela, Peru Leartzako (1959) azaldu zen eta Martutenen bigarrenez kartzelaratu zuten ETAk uztailaren 18an, "Altxamendu Nazional Ospetsuaren" jaiegunean, burututako indarkeriazko lehenengo ekintzarengatik.

\footnotetext{
1 - Joxean Agirre. Hitza hitz. Txillardegirekin solasean, Donostia, Elkar, 1996:127.

2 - Jose Luis Álvarez Enparantza, Txillardegi. Euskal Herria Helburu, Tafalla, 1994:318.

3 - Ibid.: 140.

4 - Joxean Agirre. Hitza Hitz. Txillardegirekin solasean: 127.

5 - Jose Luis Álvarez Enparantza. Euskal Herria Helburu:304.

6 - Ibid.: 138 .

7 - Ibid.:142.
} 
Aske geratu ondoren, atzerrira joatea erabaki eta 1961an Dantxarineako muga zeharkatu zuen. Une horretan bertan hasi zuen Hego Euskal Herritik kanpo emandako hamasei urteko aldia (1961-1977). Jarraian Parisera joan zen eta Sorbonako Unibertsitatean matrikulatu eta han hizkuntzalaritza lizentziatura lortu zuen. 1965ean polizia frantsesak Frantziako lurretik bota zuen eta bere familiarekin batera Belgikara alde egitera behartuta egon zen. 1967an, ETAren zuzendaritza berriak hartutako bide marxista-leninistarekin bat ez zetorrenez, harekiko harremana hautsi zuen (1965ean kanporatua izan ondoren bazegoen nahikoa hoztuta $)^{8}$. Tarte horretan Branka aldizkarian kolaboratzen hasi zen eta hizkuntzalaritzaz eta euskararen garrantziaz bi artikulu idatzi zituen. 1968an Belgikan konfinatuta zegoen, bakarrik sentitzen zen eta, horren ondorioz, bakardadea uxatzeko, Waterlootik hurbil (Brusela ondoan) bere hirugarren nobela, Elsa Sheelen (1968) idaztea erabaki zuen. 1969. urtearen bukaera aldean konfinamendua hautsi eta Frantziako Gobernuaren baimenik gabe Hego Euskal Herrian aurkeztu zen. Geroago, 1970ean, T. Monzonekin batera "Fronte Abertzale" bat sortzen saiatu zen, baina Frantziako Barne Ministerioaren agindu baten bidez biak Nogaron-era (Gers-eko Departamendua) kanporatu zituzten, non sei hilabete eman zituzten. Bestetik, Burgosko Prozesua (1970-1971) zela-eta, Euskal Herriko bi aldeetan jarduera politikoa areagotuz joan zen; Baionako katedralean Burgosen epaitutako ETAko presoen aldeko zenbait gose greba egin ziren eta haietako batean Txillardegik P. Lartzabal (1915-1988) eta T. Monzón bezalako beste euskal idazle batzuekin batera parte aktiboa hartu zuen. Euskal Herrian izandako egonaldi horretaz baliatuz, J. Haritschelharren laguntzari esker, Bordeleko Unibertsitatean euskara "irakurle" plaza lortu zuen.

1977 an, F. Franco hil eta handik bi urtetara, Txillardegi azkenik bere sorterrira itzuli ahal izan zen eta 1977eko ikasturtean euskal fonologiari buruzko ikastaroak jesuiten unibertsitate kanpusean eman zituen. Urte horretan bertan euskaltasuna eta sozialismoa aldarrikatzen zituen ESB (Euskal Sozialisten Biltzarra) alderdian sartu zen eta 1988an egotzi egin zuten. 1981-1982 ikasturtean bere emaztearekin batera Californiako Unibertsitatean (UCLA) doktore tesia prestatzeko urte sabatikoa iragan zuen. Tesia 1983an Joan Mascaró-ren zuzendaritzapean Bartzelonako Unibertsitate Autonomoan defendatu eta 1984an Euskal Azentuaz izenburua zuela argitaratua izan zen. 80ko hamarkadaren hasieran Herri Batasuna-n (H.B.) sartu eta bi legegintzalditan senadore izan zen. 90eko hamarkadan Euskal Unibertsitate Publikoan (UPV-EHU), Donostiako kanpusean, 2.000ko udan erretiratu arte, iraskale aritu zen. Erretiroa zela-eta, Udako Euskal Unibertsitateko (UEU) lagunek bere omenez Txillardegi. Lagun giroan liburua argitaratu zuten.

Sarrerako aurkezpen biografiko honen ostean haren lehen eleberria aztertuko dugu, horretarako lehendabizi euskararen alorrean egin duen lan obra literarioa garrantzitsua labur bilduko dugu. Bere obrarik aipagarrienen artean honako hauek ditugu: Sustrai bila (1970), Hizkuntza eta Pentsakera (1972), Euskara batua zertan den (1974), Oinarri bila (1977), Euskal Gramatika (1978), Euskal Herritik erdal berrietara (1978), Fonologiaren matematikuntza (1979), Euskal Fonologia (1980), 
Elebidun gizarteen azterketa matematikoa (1984), Euskal Azentuaz (1984), Soziolinguistika matematikoa (1994). Bere kolaborazioen artean aipatzekoak dira Euskal Dialektologiaren hastapenak (1987), La lengua vasca (1980) eta Euskaltzaindiaren eskariz burutu zuen Euskal Aditz Batua (1979). Euskararen alde egin duen lan ikaragarria ikusita, bere bizitzan euskarak nolako garrantzia izan duen atzematea irakurleari ez zaio asko kostatuko.

"Gure herri borrokaren ardatza hizkuntza arazoa dela sinetsirik, alor horretan eman dut neure indarren zati handi bat: bai ikerkuntzan, eta bai erabilpenaren bultzadan"10.

Aldizkarietan kolaborazio asko egin du: Egan (1956), Tierra Vasca (1960), Garaia (1976-1977), Zeruko Argia (1960-1970); baita Egin (1977-1988), Euskaldunon Egunkaria (1990) eta Gara (1999) egunkarietan ere.

Txillardegiren obra narratiboa (eleberriak, saioak eta ipuinak), batez ere bere lehenengo eleberria Leturia-ren egunkari ezkutua (1957), 50eko hamarkadaren amaieratik jauzi kualitatiboa izan zen gai eta estiloen berrikuntza ekarri baitzuen. XX. mendeko lehenengo bi hamarkadetako nobelagintza tradizional eta kostunbristaren oihartzunak urruti zeuden (Tx. Agirre, J. Etxeita e.a.). Bestetik, gerraosteko eleberrigileek (A. Anabitarte, N. Etxaniz, E. Erkiaga, A. Zubikarai, J. Etxaide eta J.A. Loidi) beren eleberri post-erromantiko, historiko eta poliziakoez ez zuten berrikuntza handirik ekarri. Egoera horretan Txillardegiren lehenengo liburuaren argitalpena ekarpen berritzailea izan zen, orduko euskal irakurle kopuru txikiarentzat oharkabean iragan ez zena. Idazle donostiarrak arrakasta handia lortu zuen eta, esate baterako, L. Mitxelenak hurrengo hitzez agurtu zuen: "[...]baldin nere iritzia estalkirik gabe agertu bear badut, eztut uste iñoiz gure izkuntzan entzun denik orrelako itz larririk"11. Zalantzarik gabe, Errenteriako hizkuntzalari ospetsuak existentzialismoan oinarritutako giza bizitzaren ikusmolde berria ikusten du, hain zuzen eleberri hori kutsatzen duena. Idealismo kantiar eta post-kantiar eta fenomenologia garbi edo zientzia existentzialista tradizionalari buruzko doktrinak existentzialismoak bazterrean utzi zituen garaia urruti zegoen (alderdi teista zein ateoa). S. Kierkegaard, M. Heidegger, K. Jaspers, M. de Unamuno, G. Marcel, M. Merleau-Ponti (1908-1961), J.P. Sartre e.a. izan genituen existentzialismo horren aldarrikatzaileak. Filosofia berriaren formularen arabera "izatea esentziatik dator", eta existentziak aurrea hartzen dio esentziari. Gizaki "kokatua" aurrerantzean aipatutako filosofarien arreta gune bihurtu zen.

\section{Leturia-ren egunkari ezkutua (1957)}

Txillardegi gazteak existentzialismoa eta budismoa gogozkoagoak zituen sasoi hartako korronte literario unibertsalak baino (v.g: "nouveau roman" frantsesa eta "errealismo magiko" latinoamerikarra). Prosa hiritar eta moderno batez, euskal

10 - Jose Luis Álvarez Enparantza. Euskal Herria Helburu: 137.

11 - Jose Luis Álvarez Enparantza. Leturia-ren egunkari ezkutua. (2a ed., Durango. L. Zugaza, editor, 1977:10). 
literaturari bide berriak irekiz, iraganeko euskal narratiba bukoliko eta landatarra gainditzen saiatu zen. Bere eleberriak, oro har, tesiak dira eta eduki ideologiko nabarmena dute; halaber, Euskal Herriko borroka politiko eta berrikuntza linguistiko eta literarioaz arduratuta dagoen intelektual baten lumaren emaitzak dira. Horregatik, sarritan bere sentimenduak eta uste existentzialistak eleberrietako pertsonaiak bilakatzen ahalegintzen zen.

1956an, K. Mitxelenak bultzatuta, Cabo Priorren (Galiziako El Ferroletik hurbil) Itsas Armadan destinatutako alferiz gazteak soldadutza unibertsitarioko aisialdia bere arma literarioak zaintzeko erabili zuen, Unamunoren antzera, barneko kezka existentzialistak ustuz. Asmo literario handirik ez bazuen ere eta bere bizitzan idazle lana bigarren mailako zeregintzat hartzen bazuen ere, eleberri hau bi hilabetetan bukatu ahal izan zuen; eta 1957an, L. Mitxelenaren hitzaurre interesgarri batek lagunduta, argitaratua izan zen ${ }^{12}$. Agerikoa denez, lehen liburuaren erronkak gazte euskaldunberri donostiar hau ez zuen izutu lana oso epe laburrean amaitu zuelako. Hori hala izan zen neurri handi batean M. de Unamunok eta J.P. Sartrek azaldutako existentzialismoa ezagutzen baitzuen. Txillardegik behin baino gehiagotan $L^{\prime} \hat{E} t r e$ eta le Néant (1943) liburua, eduki filosofiko iluna zuela-eta, ulertzeko zailtasunak zituela adierazi duen arren, haren kide literarioa ulertzeko, ordea, ez zuen zailtasun bat ere izan: Sartreren lehenengo eleberria, La nausée (1938). Ondorioz, ez da zaila Sartreren lehen eleberri honen eta Txillardegiren lehen eleberriaren arteko paralelismoak aurkitzea. Izan ere, bien protagonista nagusienek (Antoine Roquentin eta Joseba Leturia) beren egunkarietan giza existentziari buruzko barneko iritziak jasotzen dituzte: angustia existentziala, gizakiaren patua, askatasun beharra, bizitzaren monotonia, bakardade metafisikoa, e.a. Hein handi batean, bietan pertsonaren existentzia "likits", babesgabe, urduri eta zentzugabeari buruzko azterketa psikoanalitikoa egin daiteke. Hori dela-eta, bi protagonistek bizitza era tragikoan galduz bukaera txarra izango dute. Leturariarentzat Mirenekin ezkontzeak, Pariserako ihesbide bidaiak edo, azken unean, Jainkoarengana jotzeak ez du ezertarako balio izango, zeren Beronek bere eskariak ez baititu entzungo. Leturia uneoro hautatzera kondenatua bizi da, Miren bere emazte gaztearekiko harremanak hobetzeko ahalegin guztiak alferrekoak direla eta ezinbestez porrotera doazela jabetuta. A. Roquentinen gisara, bere egunkariko orrialdeak idaztean nazka sentsazioa ("dégoût") edo higuin okaztagarria zuen, Leturia arraru eta moldagabe sentituko da eta erabateko porrot eta bakardade sentimenduak bere burua hiltzera eramango du.

Eleberri honen azterketa sakonago batek erakusten digu bere egituran lau urtaroetan kokatutako egunkaria dela. Behar bada, hobe genuke hiru urtarori buruz hitz egitea, zeren Leturiak, ezkonberria denez, udan ezer ez baitu idatzita uzten. Halaber, urtaro bakoitza ataletan zatituta dago (kapitulu modukoak), burualdean zenbaki bat dutela. 1. Udaberria. Lehenengo zati luze honetan 23 atal daude. Udaberrian bi pertsonaia nagusien artean (Leturia eta Miren) maitasunaren lorea sortzen da, geroago ezkontzaz lotzeko. Ezbairik gabe, urtaro hau dugu liburuaren zatirik erromantikoena eta poetikoena eta, ikuspuntu literariotik, hobekien egindakoa. Eleberrian agertzen diren tokiak: parkea, urmael biribila, iturria, 
Altzurain, "zerubide", itsasoa, Mirenen edertasuna (17 urteko neskatxa gaztea) ditugu bizitzaren zorionaren sinbolo eta protagonistaren aldetik Absolutuaren aurkikuntza. Bera pozik sentitzen da eta Mirenen bidez Absolutu hori lortu duelakoan dago. 2. Uda. Leturiaren egunkaria zuri agertzen da urtaro horretan, bere ezkontzaren ostean ez baitu ezer idatzi. Baina, teknika zahar batez baliatuz, adibidez Camilo José Celak (1916-) La Familia de Pascual Duarte (1942) bere lehen eleberrian erabilitakoa, egileak hutsune hori lau orrialdez betetzeko (73-76) transkribatzaile bat hartzen du. Pertsonaia horren atzetik egilea bera ezkutatzen da eta, beste argibide batzuen artean, irakurleari jakinarazten dio udari dagokion zatia zergatik dagoen zuri. 3. Udazkena. Urtaro honek hamabost atal ditu. Udazkeneko osto zimelen erorketa eta Leturia eta Mirenen ezkontzaren porrota batera gertatzen dira. Gatazka sortu eta eztabaida piztu egiten da. Leturiarentzat lehenengo proiektuaren porrotari eta Absolutuaren bila hautatzen jarraitzeari aurre egiteko unea heldu da. Orain, irrikaz nahi zuen askatasuna erdietsita, Absolutua Pariserako ihesbide bidaia baten forman aurkeztuko zaio.

Laugarren zatia neguari dagokio. Parisera iritsita, Leturia haurtzaroan bezain libre sentitzen da. Hasieran argien hiriko alderdi eta monumentuen edertasunaz liluratuta geratzen da: Garaipenaren Arkua, Boulogneko Basoa, Konkordiaren Plaza, e.a. Baina berehala aldartea gain behera datorkio eta makalaldian sartzen da. Ohiko gogoeta existentzialetan murgilduta, egonezinak urratua sentitzen da. Bizitza honi jasaezin deritzo, baina bestea iritsiezina iruditzen zaio. Lizardiren bertso eder batean agertzen den bezala "nik ez nai eguna /biurtzerik gau"12 eta Leturiak ere gogor egiten du eguna gau bihur ez dadin. Berriz ilusioa bilatzen du, Absolutua. Baina norengana jo?. Estualdi horretan dagoela, bere emaztearen gutun bat jasotzen du eta beronek gaixotasun larria duela adierazten dio. Berriro ere Leturiak hautua egiten du eta Altzurainera itzultzea erabakitzen du. Mirenek sinesten duen Jainkoari otoitz egitea baino beste biderik ez zaio geratzen. Baina, protagonista hiltzen denez, ahalegin horretan ere huts egiten du, aurrekoetan bezalaxe. Etengabeko porrot kate horretan giza bizitza doa. Baina bera ez da alde egiten duena, gizakia baita betiko alde egiten duena, Leturiaren kasuan legez. "La vie s'en va... la vie non, mais nous nous en allons" ${ }^{13}$. Narratzaileak egunkariaren edukia kontatu du. Hala ere, oraindik bigarrenez agertzen den transkribatzailearen lerro argigarri batzuk geratzen dira. Bertoko Deia egunkarian agertutako albiste baten berri ematen digu: hamar egun hilda daramatzan gizon baten gorpua leize batean aurkitu dute. Txillardegik Lizardiren bertso batekin bukatzen du bere eleberria: "ots, ots... Bizion oñok!!!"14, Zarautzen haren amona hiltzean idatzia. Biziaren katea itxi egiten da azkenengo maila lehenengoarekin batzean: eleberriaren hasieran aipatzen diren tokien aipamena. Ilusioz beteriko alderdi haiek oroitzapen triste bilakatu dira. "La vie s'en va".

Eleberri honen azterketa formalak euskal narratiban berrikuntza zantzuak daudela erakusten digu. Ordurarte ohituta geunden hirugarren pertsonan egindako deskribapenak ikusten eta orain dena lehen pertsonan kontatzen duen

12 - Ibid.: 132.

13 - Ibid.: 95.

14 - Ibid.: 146. 
narratzaile bat dugu. Erreferentzia erlijioso, filosofiko, literario, linguistiko, musikal e.a. ugariek adierazten digute intelektual garaikide baten obra dela. Egileak Paris (kosmopolitismoaren eta unibertsalitatearen sinboloa) bezalako tokiak alderdi irreal eta irudizkoekin (Altzurain, "Zerubide", Izeta, Itzaspi e.a.) nahasten ditu. Denbora era kronologikoan erabiltzen duen arren (lau urtaroei jarraituz) bere garapena ez da lineala euskal nobelagintza tradizionalean gertatzen den bezala v.g: Joanesen bizitza, Garoa-ren pertsonaia nagusia.

Bukatzeko esan dezakegu eleberri honi azterketa onargarri gehiago egin ahal zaiola, eta barruan duen ezinegon existentziala ulertzeko irakurketa bat baino gehiago behar duela. Ahalegindu gara Leturiaren eta A. Roquetinen arteko paralelismo batzuk aurkezten. Ziur asko gure gaurko protagonistaren eta beste eleberri existentzialista batzuen protagonisten artean, esate baterako Kafkaren José K. eta Camusen L'Étranger elaberriaren pertsonaia nagusia Meursaulten artean, paralelismo onargarri gehiago aurki daitezke. Obra hauetan guztietan Jainkoaren isiltasuna dela-eta, gizaki abandonatuaren bilaketaren bukaeran absurdua azaleratu egiten da. 